\title{
O comportamento de compra dos consumidores de alimentos orgânicos: um estudo exploratório
}

\section{The consumer behavior in purchases of organic foods: an exploratory study}

\author{
Paulo J. Krischke ${ }^{1}$ \\ Naira Tomiello ${ }^{2}$
}

\begin{abstract}
Resumo
O objetivo deste artigo é identificar as motivações das escolhas dos consumidores por alimentos orgânicos, para tanto, foi realizada uma pesquisa qualitativa e exploratória em um supermercado de Florianópolis. O questionamento inicial aos consumidores foi "o que o (a) leva a escolher alimentos orgânicos?" Entre os principais resultados destaca-se a identificação das categorias nativas dos consumidores de tais produtos, sendo que a preocupação com a saúde foi a mais mencionada. Além disso, pode-se constatar a complexidade da temática consumo, que toma como essencial a perspectiva interdisciplinar para análise e interpretação do comportamento do consumidor.
\end{abstract}

Palavras-chave: Consumo. Alimentos orgânicos. Categorias nativas.

\section{Abstract}

The purpose of this paper is to identify the motivations for consumer choices of organic foods. A qualitative and exploratory study was conducted at a Florianópolis supermarket. The initial question posed to consumers was "what leads you to choose organic foods?" The principal results are highlighted by the identification of the native categories of the consumers of these products, given that health concerns were the most mentioned. In addition, the complexity of the issue of consumption makes an interdisciplinary perspective essential for the analysis and interpretation of consumer behavior.

Key words: Consumption. Organic foods. Native categories

\footnotetext{
${ }^{1}$ Doutor (Ph.D.) em Ciência Política pela Universidade de York (Canadá) e professor no PPGICH da UFSC.

${ }^{2}$ Doutoranda no Programa no Interdisciplinar em Ciências Humanas da UFSC, Mestre em Administração de Empresas, Graduada em Ciências Sociais e em Filosofia.
} 


\section{INTRODUÇÃO}

Canesqui (2005) comenta os estudos antropológicos da alimentação a partir de um recorte histórico. Para a autora, na década de 70 , os hábitos e as ideologias alimentares tinham como um dos focos a observação da distinção entre alimentos quente/frio; forte/fraco; pesada/leve; de rico/de pobre; boa ou má para saúde. Outro foco residia nas diferentes práticas sociais e suas significações. Importantes conclusões das pesquisas dessa época foram a identificação das marcas regionais, as associações dos alimentos à identificação de classe social, aos estados corporais e aos horários de consumo. Tais estudos sobre a alimentação visavam as classes de baixa renda. Procuravam entender o lugar da alimentação na composição dos gastos familiares, a organização da família, divisão social do trabalho na provisão, gerenciamento, controle e realização do consumo alimentar, assim como as crenças, hábitos e cardápios. Destacou-se a importância da família como estratégia de sobrevivência, especialmente a quem cabe a regra de "fazer economia".

Na década de 80 , seguindo a autora, os estudos etnográficos tornam-se mais raros, mas novas categorias são analisadas. Passa-se a associar alimentação com saúde e doença. A "boa alimentação" garante a saúde, enquanto a falta de alimentação é associada à fraqueza mental e física, por exemplo. As prevenções de doenças passam a ser analisadas a partir dos critérios dos hábitos alimentares, da manipulação dos alimentos, higiene, assim, como a evitação de bebidas alcoólicas e cigarros. Surge um discurso sobre os alimentos que fazem mal como gordurosos, e o discurso estético provenientes da valorização dos alimentos que concentram vitaminas, entre outros. O discurso estético diz respeito às classes médias e altas.

Os anos 90 e a década atual são fortemente marcados por alimentos fastfoods, que representam a redefinição das fronteiras e espaços alimentares. Também expandem-se as franchises que valorizam as etnias ${ }^{3}$, assim como a comida "a quilo" e praças de alimentação em shoppings. Há as comidas com simbolismos religiosos e outras com identidades regionais. Outras pesquisas sinalizam a associação do termo "natural" ao saudável, entretanto, esse termo

\footnotetext{
${ }^{3}$ São as comidas japonesas, mexicanas, chinesas etc.
} 
apresenta uma variabilidade de entendimentos ${ }^{4}$. A autora cita Lifschitz (1997), que mostra que o campo alimentar é sensível às mudanças culturais, como por exemplo: a ecologização, a feminilização, o orientalismo e a medicalização. Canesqui (2005) conclui que novas formas de produção e consumo se redefinem no espaço e no tempo da sociedade moderna e tal movimento necessita o deslocamento de olhares antropológicos para novos lugares.

Mas que novos lugares são esses? Entende-se, segundo Maciel (2005, p. 49), que "comida não é apenas uma substância alimentar [...]. E o jeito de comer define não só aquilo que é ingerido, como também aquele que o ingere". Singer e Mason (2007) também compreendem que o ato de comer é revelador sobre as pessoas. Para ele, comer pode ser pensado sob o ponto de vista da ética e moral tanto quanto roubar, mentir ou prejudicar outras pessoas. Para os autores, muito embora a forma de produção, distribuição e pressão publicitária dos alimentos dificultem aos consumidores escolhas conscientes, os resultados das escolhas alimentares individuais impactam sobre os demais seres e o meio ambiente. $O$ movimento em direção de uma nova consciência alimentar tem ocorrido, por exemplo, pela mobilização de ONGs que denunciam os maus tratos e as consequências no processo de criação e abate dos animais ${ }^{5}$, assim como pela mobilização na direção da produção e consumo de produtos orgânicos ${ }^{6}$.

Assim, toma-se como um novo lugar a nova consciência alimentar, que pressupõe que a escolha ética implica no conhecimento de como, onde e de que modo os alimentos são produzidos e comercializados. No caso dos produtos orgânicos, cujo crescimento e a expansão do mercado produtor e consumidor

\footnotetext{
${ }^{4}$ A representação do "natural" pode significar: para tribos alimentares significa "artesanal e natureza"; para os profissionais da saúde significa "adequação entre as propriedades dos alimentos e os requisitos fisiológicos"; para as indústrias corresponde a "produtos sem aditivos"; e para os publicitários diz respeito a um "signo de marca comercial" (LIFSCHITZ, 1997 apud CANESQUI, 2005, p. 40).

${ }^{5}$ Além de Peter Singer e Mason (2007), sugere-se o estudo crítico em defesa dos animais da Dra Sônia Felipe (2003).

${ }^{6}$ A produção e o consumo de alimentos orgânicos têm sido largamente estudados pelo Instituto de Pesquisa em Riscos e Sustentabilidade - IRIS, da Universidade Federal de Santa Catarina - UFSC, coordenado pela professora Dra Julia Silvia Guivant.
} 
tornam-se expressivos ${ }^{7}$, revela uma nova consciência que tem sido analisada seguindo, principalmente, a preocupação com o meio ambiente, com o bem-estar e como um modo de ação política.

Para Singer e Mason (2007, p. 217) as pessoas compram produtos orgânicos porque "acreditam que métodos mais naturais de produzir alimentos têm mais chances de serem saudáveis". Eles também descrevem os benefícios ambientais da produção orgânica citando a manutenção da qualidade do solo; a promoção da biodiversidade; a redução da poluição; a redução do consumo de energia, entre outros, como fatores que determinam a escolha. Os autores concordam que a opção alimentar deve seguir princípios éticos e sinalizam cinco: a) transparência (consumidores bem informados sobre as condições dos produtos que compram); b) justiça (produção não deve infringir custos a outros, como o prejuízo ao meio ambiente para as gerações futuras); c) humanidade (ter compaixão em lugar do sofrimento dos animais); d) responsabilidade social (condições dignas de trabalho); e) necessidade (escolha nutricional não deve ser motivada pela tradição ou sabor, quando essa escolha infringir padrões éticos e puder ser substituída por outras fontes nutricionais).

Além da perspectiva ética acima mencionada, Guivant (2003) destaca a aproximação entre a sociologia e a antropologia para compreender a escolha alimentar humana. Tal aproximação é recortada pela autora sob o conceito de "estilo de vida", e cita Giddens (2002 apud GUIVANT, 2003, p. 64) que o define como sendo "um conjunto de práticas sociais que um indivíduo assume, junto com a narrativa sobre a auto-identidade, que o acompanha". A autora adota a caracterização do estilo de vida a partir dos conceitos ego-trip e ecologico-trip de Guillon e Willequet. O estilo de vida ego-trip corresponde ao interesse dos indivíduos de autopreservação e autopromoção, sustentando, assim, o foco na segurança e qualidade dos alimentos e no discurso da beleza, saúde e boa forma. Por outro lado, o estilo de vida ecológico-trip representa um contato simbólico entre o consumidor e seu ambiente, ou seja, "quem procura o consumo orgânico como

\footnotetext{
7 Para conhecer o cenário mundial da produção e demanda de produtos orgânicos, sugere-se: www.ifoam.org (Federação Internacional de Movimentos de Agricultura Orgânica - IFOAM); www.cedeco.or.cr (Corporación Educativa para el Desarrollo Costarricense - CEDECO); www.planetaorganico.com.br (Planeta Orgânico); www.soel.de (Foundation Ecology \& Agriculture SÖL).
} 
parte de uma atitude assumida frente ao meio ambiente ou de responsabilidade social". (GUIVANT, 2003, p. 64).

A nova consciência alimentar também é abordada a partir da politização das práticas de consumo. Segundo Portilho (2005), a partir dos anos 90 a crise ambiental foi redefinida pelo deslocamento dos problemas relacionados à produção para os relacionados ao consumo. O estilo de vida ostentatório, antes enfatizado pela iniquidade de classe, agora passa a significar uma iniquidade intergeracional. Expressões como "consumo verde" e "consumo sustentável" tornam-se constantes para caracterizar a esfera de consumo como uma nova possibilidade de ação política. A autora ainda completa dizendo que há nichos de mercados específicos para "negros, homossexuais, solteiros, naturalistas, idosos, crianças, adolescentes e, por que não, ambientalistas?" E conclui que "o nível e o estilo de consumo se tornaram a principal fonte de identidade cultural e de participação na vida coletiva, além de caminhos privilegiados para a análise e compreensão das sociedades contemporâneas". (PORTILHO, 2005, p. 27).

Maciel (1986, p. 8 apud CANESQUI, 2005, p. 42) também contribui para compreender a dimensão do consumo alimentar a partir do privilégio da carga simbólica deste, dizendo que comida

não é apenas boa para comer, mas boa para pensar. Pensar em comida é
pensar em simbolismo, pois ao comermos, além de ingerirmos nutrientes
(que permitem a sobrevivência), ingerimos também símbolos, idéias,
imagens e sonhos (que permitem uma vivência).
elaborado por determinado grupo tanto sob seus aspectos simbólicos quanto materiais pode ser compreendido a partir das categorias nativas difundidas por eles. Tais categorias tornam legítima a identidade de um nós coletivo. (CUNHA, 1986). Assim como, podem representar um código, cujo aprendizado das regras permite a comunicação e o compartilhar de experiências comuns. (MONTEIRO, 2006).

A partir da síntese elaborada, cabe perguntar: Quais são as categorias nativas dos consumidores de produtos orgânicos? Em que medida é possível distinguir as ênfases entre as condições materiais e as condições simbólicas no consumo de tais produtos? Como os consumidores de produtos orgânicos interpretam tal consumo? 
Por meio de uma pesquisa de campo de caráter exploratório, buscou-se identificar algumas respostas para tais indagações. Optou-se por abordar consumidores em um ponto de vendas de produtos orgânicos, especificamente os do setor de frutas, legumes e verduras (FLV) em um supermercado de Florianópolis. Diante das gôndolas de produtos orgânicos (FLV), a pesquisadora investigou a motivação para o consumo de orgânicos por meio da questão: "o que o(a) leva a escolher os alimentos orgânicos?". Informações adicionais sobre o objeto da pesquisa foram acrescidas mediante a observação direta.

\section{RESULTADOS DA PESQUISA DE CAMPO}

Com o objetivo de melhor explorar a apresentação dos resultados ao questionamento "o que o(a) leva a escolher os alimentos orgânicos?", optou-se por apresentar: a) quadro com resumo de 20 depoimentos; b) narrativa do depoimento de um professor universitário, cujo o número de categorias nativas excedeu-se em relação aos demais; c) Inconsistências observadas

\section{a) Resumo de 20 depoimentos}

O quadro 01 apresenta uma caracterização do perfil do respondente, as categorias nativas e uma síntese dos respectivos depoimentos. Caracterizou-se sinteticamente o perfil com o propósito de situar os depoimentos, sem a identificação dos respondentes. Não foram realizadas perguntas específicas para a compreensão das características demográficas. A caracterização partiu da observação da pesquisadora e, em alguns casos, da declaração espontânea dos entrevistados. As categorias nativas são palavras-chave retiradas dos depoimentos. Elas sintetizam a percepção dos respondentes sobre as razões que os levam a consumir ou não os produtos orgânicos. O quadro 01 totaliza o resultado de 20 entrevistas. 
Quadro 01: Depoimentos dos Consumidores

\begin{tabular}{|c|c|c|c|}
\hline $\mathbf{N}^{\circ}$ & Perfil & Categoria Nativa & Síntese dos Depoimentos \\
\hline 1. & Homem branco jovem & $\begin{array}{l}\text { - } \text { Qualidade do } \\
\text { produto } \\
\text { - Sem agrotóxico }\end{array}$ & "Qualidade do produto, não tem agrotóxico". \\
\hline 2. & Casal branco jovem & $\begin{array}{l}\text { - Não priorizamo } \\
\text { consumo } \\
\text { - Preço é fator } \\
\text { determinante }\end{array}$ & $\begin{array}{l}\text { "Não priorizamos o consumo de orgânicos, sabemos } \\
\text { dos benefícios, mas o preço é um fator determinante } \\
\text { para não consumirmos". }\end{array}$ \\
\hline 3. & Mulher branca jovem & $\begin{array}{l}\text { Consumo } \\
\text { condicionado }\end{array}$ & $\begin{array}{l}\text { "Não olho muito, não. Compro orgânico quando não } \\
\text { têm do outro". }\end{array}$ \\
\hline 4. & $\begin{array}{l}\text { Homem branco de } \\
\text { meia idade }\end{array}$ & $\begin{array}{l}\text { - } \quad \text { Saúde } \\
\text { - } \quad \text { Sem agrotóxico }\end{array}$ & "Tem menos agrotóxico e isso é bom para a saúde". \\
\hline 5. & Mulher branca jovem & $\begin{array}{l}\text { - Consumo } \\
\text { esporádico }\end{array}$ & $\begin{array}{l}\text { "Meu consumo não é frequente, não priorizo. Apenas } \\
\text { gosto". }\end{array}$ \\
\hline 6. & Homem branco jovem & - Desconhece & "O que é orgânico? Estou comprando temperos." \\
\hline 7. & Mulher branca jovem & - Depende do preço & $\begin{array}{l}\text { "Compro dependendo do preço, mas meu sogro, que é } \\
\text { ambientalista, sempre me aconselha e a meu marido a } \\
\text { consumirmos produtos orgânicos"; }\end{array}$ \\
\hline 8. & $\begin{array}{l}\text { Senhora branca de } \\
\text { meia idade }\end{array}$ & $\begin{array}{l}\text { - Saúde } \\
\text { - Confiança na } \\
\text { marca }\end{array}$ & $\begin{array}{l}\text { "Consumo por causa dos benefícios à saúde. Tenho } \\
\text { uma marca em especial que confio mais. Os preços } \\
\text { deveriam chegar mais baratos ao consumidor". }\end{array}$ \\
\hline 9. & Casal branco jovem & $\begin{array}{l}\text { - } \quad \text { Saúde } \\
\text { - } \quad \text { manfiança na } \\
\text { - } \quad \text { Não agride a } \\
\text { natureza }\end{array}$ & $\begin{array}{l}\text { Homem: "faz bem à saúde. Esperamos que sejam } \\
\text { confiáveis. A princípio, confiamos na marca do } \\
\text { supermercado". } \\
\text { "Além da saúde, entendemos que ajuda a não agredir } \\
\text { a natureza". }\end{array}$ \\
\hline 10. & $\begin{array}{l}\text { Homem branco de } \\
\text { meia idade }\end{array}$ & $\begin{array}{l}\text { - Saúde } \\
\text { - Ecossistema se } \\
\text { auto-redefine }\end{array}$ & $\begin{array}{l}\text { "Consumo por causa da saúde. O ecossistema não é } \\
\text { um problema, porque ele é complexo e se auto- } \\
\text { redefine". }\end{array}$ \\
\hline 11. & $\begin{array}{l}\text { Homem branco, na } \\
\text { terceira idade (italiano) }\end{array}$ & $\begin{array}{l}\text { - } \quad \text { Saúde } \\
\text { - } \quad \text { Pouca oferta } \\
\text { - } \quad \text { Duram menos }\end{array}$ & $\begin{array}{l}\text { "Consumo porque creio que faz bem à saúde. O } \\
\text { problema que há poucos produtos que são orgânicos. } \\
\text { Há produtos importados com qualidade superior aos } \\
\text { nacionais e por isso eu os priorizo. A desvantagem dos } \\
\text { produtos orgânicos é que eles duram menos na } \\
\text { geladeira que os demais. Assim, quando sei que vou } \\
\text { consumir rapidamente, compro orgânico". }\end{array}$ \\
\hline
\end{tabular}




\begin{tabular}{|c|c|c|c|}
\hline 12. & $\begin{array}{l}\text { Mulher branca de meia } \\
\text { idade }\end{array}$ & - Saúde & $\begin{array}{l}\text { "Consumo produtos orgânicos porque são mais } \\
\text { saudáveis". }\end{array}$ \\
\hline 13. & $\begin{array}{l}\text { Homem branco, na } \\
\text { terceira idade } \\
\text { (Advogado e professor } \\
\text { aposentado) }\end{array}$ & $\begin{array}{l}\text { - } \quad \text { Qualidade de vida } \\
\text { Consumidores } \\
\text { desconhecem e } \\
\text { compram por } \\
\text { indução } \\
\text { - Vendedores como } \\
\text { instrutores } \\
\text { Orientação mais } \\
\text { eficiente }\end{array}$ & $\begin{array}{l}\text { "Consumo porque desejo maior qualidade de vida. Não } \\
\text { tenho restrições relativas ao preço. Percebo que grande } \\
\text { parte dos consumidores não tem conhecimento para } \\
\text { distinguir e compram por indução. Os proprietários de } \\
\text { supermercados não percebem a importância de } \\
\text { regulamentar uma orientação mais eficiente aos } \\
\text { consumidores. Poderiam ser proporcionados cursos } \\
\text { aos vendedores sobre a propriedade dos alimentos. } \\
\text { Assim, estariam ajudando a prevenir, por exemplo, a } \\
\text { obesidade. Você vai ao setor de vinhos e há alguém lá } \\
\text { explicando tudo sobre o assunto. Aqui no setor de } \\
\text { alimentos saudáveis, não há ninguém". }\end{array}$ \\
\hline 14. & $\begin{array}{l}\text { Senhora branca de } \\
\text { meia idade }\end{array}$ & $\begin{array}{ll}\text { - } & \text { Saúde } \\
\text { - } & \text { Manejo } \\
\text { - } & \text { diferenciado } \\
\text { Solo tem } \\
\text { capacidade } \\
\text { revitalizadora }\end{array}$ & $\begin{array}{l}\text { "Consumo porque é bom para a saúde, sei que há um } \\
\text { manejo diferenciado dos alimentos. O meu foco é a } \\
\text { saúde, já que foi comprovado que o agrotóxico não } \\
\text { prejudica, tendo em vista que o solo tem capacidade } \\
\text { revitalizadora". }\end{array}$ \\
\hline 15. & Mulher branca jovem & - Saúde & "O que me leva a consumir é porque faz bem à saúde". \\
\hline 16. & $\begin{array}{l}\text { Homem branco na } \\
\text { terceira idade }\end{array}$ & $\begin{array}{l}\text { - Confiança na } \\
\text { marca } \\
\text { - } \quad \text { Vida saudável }\end{array}$ & $\begin{array}{l}\text { "O importante é confiar na marca do produto que você } \\
\text { está comprando. Eu compro porque desejo uma vida } \\
\text { mais saudável". }\end{array}$ \\
\hline 17. & $\begin{array}{l}\text { Mulher branca de meia- } \\
\text { idade }\end{array}$ & $\begin{array}{l}\text { - Sabor e preço } \\
\text { - } \quad \text { Como errado }\end{array}$ & $\begin{array}{l}\text { "Consumo de produtos orgânicos está condicionado ao } \\
\text { sabor e ao preço". } \\
\text { "Como errado, sim, apesar do médico solicitar ao } \\
\text { contrário". }\end{array}$ \\
\hline 18. & Mulher branca jovem & $\begin{array}{l}\text { - } \quad \text { Alimentos crus } \\
\text { - } \quad \text { Comemos de tudo }\end{array}$ & $\begin{array}{l}\text { "Só consumo alimentos crus, quando tenho que } \\
\text { cozinhar priorizo os não-orgânicos". } \\
\text { "Na minha casa comemos de tudo, do bolo integral ao } \\
\text { bolo de marshmallow". }\end{array}$ \\
\hline 19. & $\begin{array}{l}\text { Mulher oriental de } \\
\text { meia-idade }\end{array}$ & $\begin{array}{l}\text { - } \quad \text { Saudável } \\
\text { - } \quad \text { eituras e } \\
\text { televisão para } \\
\text { obter informações }\end{array}$ & $\begin{array}{l}\text { Disse que consumia produtos orgânicos porque era } \\
\text { mais "saudável". } \\
\text { Indagada sobre como ela obtém informações sobre os } \\
\text { alimentos "saudáveis", ela disse: "por meio de leituras } \\
\text { e televisão". } \\
\text { Disse que quem cozinha em sua casa é a sua } \\
\text { "secretária" }\end{array}$ \\
\hline
\end{tabular}




\begin{tabular}{|c|l|l|l|}
\hline 20. & $\begin{array}{l}\text { Mulher branca de meia- } \\
\text { idade } \\
\text { caros } \\
\text { - } \begin{array}{l}\text { Saudáveis } \\
\text { "Os demais produtos orgânicos, como arroz, açúcar etc } \\
\text { são muito caros". }\end{array}\end{array}$ & $\begin{array}{l}\text { Demonstrou entusiasmo pelos produtos "saudáveis". } \\
\text { Prioriza o consumo dos orgânicos, mas se estes } \\
\text { estiverem "feios", optará por outros produtos. }\end{array}$ \\
\hline
\end{tabular}

Fonte: Dados primários.

O quadro 01 revela os argumentos em duas direções: uma que justifica o porquê do consumo de produtos orgânicos, outra, traz justificativas para a restrição do seu consumo.

Quanto às razões do consumo, destacam-se as categorias nativas saúde, saudável, vida saudável e qualidade de vida. Esta constatação coincide com o resultado da pesquisa de Guivant (2003, p. 78), para quem "o consumidor dos alimentos orgânicos nos supermercados estaria mais próximo do ego-trip, numa procura por alimentos saudáveis [...]".

Entre as categorias citadas com menor frequência estão a confiança na marca e a qualidade do produto. Entre as razões do consumo que beneficiam o meio ambiente foram mencionadas que não agride a natureza e tem um manejo diferenciado da terra. A ausência de agrotóxico era associada à saúde e não ao meio ambiente. Ainda, além das preocupações com o meio ambiente terem sido pouco citadas como justificativas para o consumo de orgânicos, houve duas citações que se referiam à capacidade revitalizadora do solo, assim como, que o ecossistema não é um problema. Ou seja, além da amostra pesquisada contrariar a perspectiva estuda por Portilho (2005, p. 35) de que a "esfera do consumo surge com uma nova possibilidade de ação política [consumo verde, p.ex.]", ainda negam a tese da "finitude dos sistemas naturais".

Quanto ao fator restritivo ao consumo, o preço foi a categoria mais citada. Seguida pelas categorias de pouca oferta, produtos duram menos, consumo esporádico e o consumo apenas de alimentos crus.

$\mathrm{Na}$ avaliação de um dos entrevistados, os consumidores desconhecem do que tratam os produtos orgânicos, apenas compram por indução. Ainda, criticou a 
postura do supermercado por não manter profissionais aptos e disponíveis para explicarem sobre as especificidades dos produtos saudáveis, no caso, os orgânicos.

As categorias nativas mencionadas tanto sob o ponto de vista da motivação, quanto dos fatores limitantes para o consumo mostram-se restritivas em relação à literatura. A revista "Primeiro Plano: responsabilidade social e desenvolvimento sustentável" (2006) sintetizou as motivações por meio das seguintes categorias: a comida fica mais gostosa; não há substâncias químicas; ajuda a proteger gerações futuras; protege a qualidade da água; há menos gastos com nutrição; não prejudica o solo; contribui para o trabalho do pequeno produtor; restaura a biodiversidade; reduz o aquecimento global e economiza energia; e contribui para uma vida saudável. Por outro lado, os fatores limitantes para o consumo são: os preços altos ocasionados porque a demanda é maior que a oferta; falta de informação dos consumidores sobre a abrangência dos seus benefícios; falta de incentivos agrícolas; estilo de vida arraigado às tradições de consumo; e canais de distribuição ainda restritos.

\section{b) Narrativa de um depoimento}

Em minha última entrevista indaguei um homem, branco, meia-idade e professor universitário. Ele me disse que consome diariamente produtos orgânicos, mas que prefere comprá-los na feira. Demonstrou preocupação em relação a "crença no que não controlamos", ao referir-se se podemos acreditar ou não que de fatos os produtos sejam orgânicos. Reconhece que sua esposa crê mais nos benefícios e estimula o consumo familiar. Porém, argumenta sobre "um certo ar de modismo, sobretudo pela dúvida de como é realizado o controle". Outro problema levantado pelo professor foi a questão dos preços. Para ele "vender algo como orgânico pode ser uma estratégia de segmentar um produto e elevar seus preços". Argumentei sobre a lei da oferta e da procura. Nessa situação, ele ponderou sobre a demanda e citou a professora Julia Guivant como sendo uma pesquisadora que acompanha a "euforia" desse consumo. Em discussão com amigos, percebe a tendência cada vez maior ao consumo. E completa: "quanto mais for divulgado, maior será o consumo e menor o preço". Lembrou-se, ainda, de trabalhos em forma de cooperativas cujos integrantes (produtores) exercem o controle uns sobre os 
outros e que isso é uma forma de passar maior credibilidade aos consumidores. Salientou também o trabalho de um outro professor da Universidade Federal, Wilson Schmidt, que trabalha em uma ONG chamada Agreco e que participou do projeto governamental "Agenda Técnica para a proposta governamental de abolição do uso de agrotóxicos em Santa Catarina". Essa ONG tem foco voltado à educação ambiental. $\mathrm{O}$ entrevistado acredita que uma resistência ao consumo de produtos orgânicos está atrelada ao conceito de "sociedade das aparências". Para ele, é visível que uma fruta tratada com agrotóxico é muito mais bonita e chama mais a atenção. O que é um engano, pois "beleza não significa sabor", argumenta. Acredita que jovens e crianças sejam bastante "iludidos" pela aparência. A filha de 15 anos aceita comer "segundo as regras da família", mas prefere produtos industrializados. Sobre as razões do seu consumo argumentou que poderiam estar atreladas à sua infância. Quando criança, era acostumado a comer frutas, verduras e legumes cultivados em horta própria e sem agrotóxico e "esse hábito na infância pode favorecer ao consumo de produtos orgânicos. É como se estivesse registrado na mente". Segundo ele, "a palavra 'orgânico' resgata o encanto da noção do 'natural'". Indaguei sobre outros hábitos alimentares e ele disse: "eu como carne e frequento restaurantes de comida japonesa". E arrematou: "acredito que o consumo de produtos orgânicos associados aos demais produtos traz àqueles um ar de 'sagrado'. É como se pudéssemos ser purificados mesmo pelo consumo irregular dos orgânicos". O entrevistado conclui resgatando a noção de cooperativismo. Para ele o "consumo saudável favorece o pequeno produtor, a produção consciente, o cooperativismo e as relações menos gananciosas". Agradeci a contribuição e encerrei a entrevista.

Este depoimento revelou a maior diversidade de categorias nativas entre as entrevistas realizadas. Além disso, houve maior clareza na distinção entre a dimensão simbólica e a dimensão material no consumo dos produtos orgânicos, e também quanto à abordagem ética na opção alimentar. Entre as categorias nativas do depoimento narrado, destacam-se: modismo; preocupação com a crença no que não controla; estratégia de segmentar e elevar os preços; euforia do consumo; Ong; projeto governamental; resistência ao consumo; sociedade das aparências; beleza não significa sabor; hábitos da infância; registros na mente; ar de sagrado; 
pudéssemos ser purificados; favorece o pequeno produtor; produção consciente; cooperativismo; e relações menos gananciosas.

\section{c) Inconsistências Observadas}

Parei de abordar diretamente por alguns minutos os consumidores e passei a observar os carrinhos de compras dos que passavam pelo corredor diante das gôndolas refrigeradas. Eles continham alimentos de toda a procedência: vegetais orgânicos e não-orgânicos, refrigerantes, doces, enlatados, carnes etc. Em um caso específico, chamou-me a atenção a escolha demorada de produtos orgânicos por uma mulher, branca, de meia-idade, sendo que seu carrinho continha, por exemplo, lingüiça suína e biscoitos recheados. Aproximei-me e indaguei sobre suas preferências. Ela disse que prioriza o consumo dos orgânicos, mas se estes estiverem "feios", optará por outros produtos. Disse que sua família consome produtos orgânicos diariamente, mas estão restritos aos legumes e verduras "os demais produtos orgânicos, como arroz, açúcar etc são muito caros". Ela é quem prepara os alimentos para a família e os produtos orgânicos têm melhor sabor e durabilidade [a durabilidade foi negada por outro consumidor]. Disse que é dona-decasa e não pratica esportes, já o marido é instrutor de tênis. Em nenhum momento referiu-se aos demais produtos do seu carrinho. Ao contrário, demonstrou entusiasmo pelos produtos "saudáveis", já que em sua casa há pessoas que praticam esportes. Acreditei que poderia constrangê-la se a indagasse sobre o que seu carrinho parecia revelar a respeito dos seus hábitos alimentares e optei por calar-me.

Outro ponto de inconsistência diz respeito à disposição dos orgânicos (FLV) no supermercado. $O$ espaço destinado aos produtos orgânicos consiste em uma gôndola refrigerada de aproximadamente oito metros. Havia indicações na parte superior da mesma, anunciando "produtos orgânicos". Contudo, em uma das indicações foi colado um papel sobre o "orgânico". Então, em uma mesma gôndola, que supostamente era de produtos orgânicos, havia produtos que não tinham tal origem. Esse fato associado a pouca distinção das embalagens quanto à caracterização do que é ou não orgânico, podia gerar compras indesejadas. Nenhum dos consumidores percebeu e/ou comentou tal fato. 


\section{CONSIDERAÇÕES FINAIS}

Entende-se que um resultado subliminar consiste no próprio ato de pesquisar e com isso fazer com que seus entrevistados passem a refletir [ou reflitam mais] sobre as práticas de consumo e, talvez, estendam as discussões aos seus pares. A atenção ao tema pode ser evidenciada quando dois entrevistados [após terem concluído seus depoimentos] retornaram para continuar a opinar sobre o assunto. Ou ainda, alguns ficavam por perto parecendo querer ouvir as respostas de outras entrevistas.

Outro resultado consiste em atribuir aos estudos alimentares a necessidade de "conjunção dos distintos olhares disciplinares" (CANESQUI, 2005, p. 42). Assim, a abordagem interdisciplinar é aconselhável a investigações sobre o consumidor. Fischler (1990) sustenta que a opção alimentar é uma consequência de diversos fatores como os biológicos, sociais, econômicos, culturais e psicológicos. Maciel (1996, p. 8) confirma tal perspectiva ao dizer que "a alimentação responde não apenas à ordem biológica (à nutrição), mas se impregna pela cultura e a sociedade, sendo que sua compreensão convoca um jogo complexo de fatores".

O jogo complexo de fatores é sintetizado pelas áreas que, tradicionalmente, se ocupam do estudo do comportamento do consumidor, tais como Administração e Economia. Um modelo dos fatores que influenciam o comportamento de compra é detalhado por Kotler (1996): fatores culturais (cultura, subcultura e classe social); fatores sociais (grupos de referência, família, papéis e posição social); fatores pessoais (idade e estágio do ciclo de vida, ocupação, condições econômicas, estilo de vida, personalidade e autoconceito); fatores psicológicos (motivação, percepção, aprendizagem, crenças e atitudes). McCarthy e Perreault (1997) e Ferrell et al (2000) são importantes autores que também sintetizam tal abordagem interdisciplinar para o estudo do comportamento do consumidor.

A complexidade analítica do consumo alimentar foi evidenciada neste artigo ao recortar as categorias nativas dos respondentes. Com o objetivo de evidenciar tal complexidade, o quadro 02 resume as categorias distintas por conceitos abrangentes. 
Quadro 02: Agrupamento das categorias nativas x complexidade de fatores

\begin{tabular}{|c|c|c|}
\hline \begin{tabular}{ll} 
& \multicolumn{1}{c}{ Perfil } \\
- Étnico \\
- Sexo \\
- Socioeconômico \\
- Psicográfico
\end{tabular} & $\begin{array}{l}\quad \text { Estilo de vida } \\
\text { - Saúde } \\
\text { - } \quad \text { Qualidade de vida } \\
\text { - Vegetariano }\end{array}$ & \begin{tabular}{l}
\multicolumn{1}{c}{ Crenças } \\
- $\quad$ Lembra a infância \\
- $\quad$ Ar de sagrado, de \\
purificação \\
- Sociedade de aparências
\end{tabular} \\
\hline \begin{tabular}{ll}
\multicolumn{1}{c}{ Ética } \\
- $\quad$ Relações menos \\
gananciosas \\
- $\quad$ Produção consciente
\end{tabular} & $\begin{array}{l}\text { Meio ambiente } \\
\text { - Capacidade revitalizadora do } \\
\text { - Solo } \\
\text { - Sem agrotóxicos } \\
\text { - Não agredir a natureza }\end{array}$ & $\begin{array}{ll} & \text { Comportamento de compra } \\
\text { - } & \text { Consumo individual } \\
\text { - } & \text { Consumo familiar } \\
\text { - } & \text { Consumo irregular } \\
\text { - } & \text { Consumo por modismo induzido } \\
\text { - } & \text { Euforia do consumo }\end{array}$ \\
\hline \begin{tabular}{ll} 
& \multicolumn{1}{c}{ Empresa } \\
- & Marca \\
- & Atendimento \\
- & Credibilidade \\
- Estratégia
\end{tabular} & \begin{tabular}{ll} 
& \multicolumn{1}{c}{ Produção } \\
- $\quad$ Manejo diferenciado \\
- $\quad$ Escala de produção \\
-
\end{tabular} & $\begin{array}{ll} & \text { Produto } \\
& \text { Sabor } \\
\text { - } & \text { Preço } \\
\text { - } & \text { Disponibilidade } \\
\text { - } & \text { Durabilidade }\end{array}$ \\
\hline $\begin{array}{c}\text { Mercado } \\
\text { - Nível de oferta } \\
\text { - Nível de demanda }\end{array}$ & $\begin{array}{ll} & \text { Canal de Distribuição } \\
\text { - } & \text { Supermercados } \\
\text { - } & \text { Feiras } \\
\text { - } & \text { Fonte de informação }\end{array}$ & \begin{tabular}{ll} 
& \multicolumn{1}{c}{ Projetos } \\
- $\quad$ Governamentais \\
- $\quad$ Coo-governamentais \\
Coopismo
\end{tabular} \\
\hline
\end{tabular}

Fonte: Adaptação dos dados da pesquisa.

É possível verificar a partir desta pesquisa exploratória a abertura de campos de investigação que suscita a temática consumo. Desde Canesqui (2005) que apresenta estudos antropológicos da alimentação a partir de um recorte histórico; Singer e Mason (2007) que atribuem à escolha alimentar um comprometimento ético; Guivant (2003) que procura caracterizar o consumo de produtos orgânicos seguindo o conceito de estilo de vida (ego-trip e ecologico-trip); Portilho (2005) que explora a esfera de consumo como uma nova possibilidade de ação política. E, mediante a identificação das categorias nativas de uma amostra de 
consumidores de produtos orgânicos em um supermercado de Florianópolis, ampliase à Administração, aqui mencionada a partir de Kotler (1996).

As pesquisas sobre o perfil e motivação dos consumidores de produtos orgânicos apresentam limites (GUIVANT, 2003). No entanto, defende-se que as tais pesquisas devam integrar as abordagens qualitativas e quantitativas, cuja análise interdisciplinar melhor corresponderá à complexidade da temática. 


\section{REFERÊNCIAS}

CANESQUI, A. M. Comentários sobre os estudos antropológico da alimentação. In: CANESQUI, A. M; GARCIA, RWD. Antropologia e nutrição: um diálogo possível. Rio de Janeiro: Fiocruz, 2005. p. $23-47$.

CUNHA, Manuela Carneiro da. Antropologia do Brasil: mito, história, etnicidade. São Paulo: Brasiliense, 1986.

FELIPE, T. Sônia. Por uma questão de princípios. Florianópolis: Fundação Boitex, 2003.

FERRELL, O. C. et al. Estratégias de marketing. São Paulo: Atlas, 2000.

FISCHLER, C. L'Homnivore. Le goût, la cuisine et le corps. Paris: Éditions Odile Jacob, 1990.

GUIVANT, J. Os supermercados na oferta de alimentos orgânicos: apelando ao estilo de vida ego-trip. Ambiente \& Sociedade, v.6, n. 2, jul./dez., 2003

KOTLER, P. Administração de marketing: análise, planejamento, implementação e controle. 4 ed. São Paulo: Atlas, 1996.

MACIEL, M. E. Identidade Cultural e alimentação. In: CANESQUI, AM; GARCIA, RWD. Antropologia e nutrição: um diálogo possível. Rio de Janeiro: Fiocruz, 2005. p. 23-47

McCARTHY, E. J.; PERREAULT, W. D. Marketing essencial: uma abordagem gerencial e global. São Paulo: Atlas, 1997.

MONTEIRO, Paula (org.). Deus na Aldeia: missionários, índios e mediação cultural, São Paulo, Globo, 2006.

POTILHO, F. Sustentabilidade ambiental, consumo e cidadania. São Paulo: Cortez, 2005. 
REVISTA Primeiro Plano: responsabilidade social e desenvolvimento sustentável. Florianópolis, $n^{\circ}$ 4, dez 2006.

SINGER, Peter. A ética da alimentação: como nossos hábitos alimentares influenciam o meio ambiente e o nosso bem-estar. Rio de Janeiro: Elsevier, 2007. 